\title{
Xenoma-like formations induced by Soricimyxum fegati (Myxosporea) in three species of shrews (Soricomorpha: Soricidae), including records of new hosts
}

\author{
Iva Dyková ${ }^{1,2}$, Tomáš Tyml ${ }^{1,2}$ and Martin Kostka ${ }^{1,2}$ \\ ${ }^{1}$ Institute of Parasitology, Biology Centre of the Academy of Sciences of the Czech Republic, Branišovská 31, 37005 České \\ Budějovice, Czech Republic; \\ ${ }^{2}$ Faculty of Science, University of South Bohemia, Branišovská 31, 37005 České Budějovice, Czech Republic
}

\begin{abstract}
In South Bohemia, Czech Republic, 178 shrews, including 98 common shrews, Sorex araneus L., 70 pygmy shrews, Sorex minutus L., and 10 lesser white-toothed shrews, Crocidura suaveolens (Pallas), were examined for Soricimyxum fegati Prunescu, Prunescu, Pucek et Lom, 2007 infections, using squash preparations of unfixed tissues, histological sections and molecular methods. The infection was found in 51 (52\%) S. araneus, 14 (20\%) S. minutus and 1 (10\%) C. suaveolens. The records of the latter two species extend host range of $S$. fegati. Lesions associated with $S$. fegati infections in the liver, the organ of specific localisation of the parasite, were found to be induced by proliferative stages migrating toward lumina of bile ducts. In other organs of these three host species, xenoma-like formations (XLFs) were found that severely injured blood vessels. XLFs contained presporogonic stages of S. fegati, whose species identity was evidenced using molecular methods.
\end{abstract}

Keywords: Soricimyxum fegati infections, xenoma-like formations, shrews, Sorex araneus, Sorex minutus, Crocidura suaveolens

The most recent data on Soricimyxum fegati Prunescu, Prunescu, Pucek et Lom, 2007 are those obtained by the study of infections of the common shrews (Sorex araneus L.) in South Bohemia, Czech Republic (Dyková et al. 2007). The present authors continued this research, collected additional material from common shrews and other soricid species in South Bohemia, and evaluated data with special reference to the course of infection and aetiology of lesions found in other than specific (i.e., hepatic) sites of infection. These lesions were represented by formations resembling xenomas well known from microsporidian infections.

\section{MATERIALS AND METHODS}

In total 178 shrews, including 98 common shrews, Sorex araneus L., 70 pygmy shrews, Sorex minutus L. and 10 lesser white-toothed shrews, Crocidura suaveolens (Pallas), were collected in alluvial forests in South Bohemia, Czech Republic from August 2007 to November 2009. Based on previous experience (Dyková et al. 2007), the same method was used for host collection, i.e., stationary pitfall traps, checked daily, early in the morning. Host species were determined using Aulagnier et al. (2009).

Screening of shrews for the presence and severity of S. fegati infections was accomplished using several methods. At necropsies, samples of liver, spleen, kidney with adrenal gland, dia- phragm, lungs, heart and brain were fixed in Davidson's fixative and embedded in Histoplast-S (Serva) for histology. A minimum of 20 sections from each Histoplast block were examined. Sections were routinely stained with haematoxylin and eosin, and in selected cases with Giemsa stain, Masson's trichrome for collagen or Verhoeff's stain for elastic connective tissue. Liver tissue was also examined unfixed (in squash preparations) and small pieces were fixed in 96\% ethanol for PCR diagnostics and extraction of $S$. fegati DNA as described previously (Dyková et al. 2007). Additionally, the type material (Prunescu et al. 2007) originating from the Bialowieza National Park, Poland (i.e., haematoxylin and eosin-stained sections of liver, slides Nos. DPF 012 and DPF 013 deposited in the collection of the Institute of Parasitology, Biology Centre AS CR, České Budějovice) was re-examined.

In order to determine the origin of lesions of interest, two procedures were applied. Firstly, tissue samples (originally processed for histology) were excised from Histoplast blocks, re-embedded into Spurr resin and sectioned for transmission electron microscopy. Secondly, PCR diagnostic was performed using samples embedded in Histoplast. Xenoma-like formations (XLFs) were cut off from $6 \mu \mathrm{m}$ thick semi-serial histological sections under a dissecting microscope (sections alternately stained in series indicated areas of interest in unstained sections containing XLFs). DNA was extracted using two different commercial kits: (1) Tissue DNA Spin Kit - Protocol A1 for paraffin-embedded tissue (JETQUICK) and (2) REPLI-g ${ }^{\circledR}$ FFPE kit (QIAGEN). SSU rDNA was amplified by PCR using 
three pairs of primers: Sorfeg-25F (5'-TAAGGTAGTGGCTTACCAA-3') and Sorfeg-176R (5'-CTTTTGGGAACGACCTGG-3'); Sorfeg-176F (5'-CCAGGTCGTTCCCAAAAG-3') and Sorfeg-377R (5'-GCGCGGCAAACACGCT-3'); Sorfeg563F (5'-CTGTGCGTCGTGTCTTAC-3') and Sorfeg-625R (5'-ACATTCAAGCGTCGCGCT-3'). Design of these Soricimyxum-specific PCR primers was based upon alignment of 15 SSU rDNA sequences. Eight sequences represented different myxosporean species (Soricimyxum fegati, Chloromyxum truttae, Sphaerospora hellandi, S. zaharoni, Myxidium hardella, M. chelonarum, M. truttae and Zschokkella nova). Another two sequences represented other parasites present in the shrews examined (the protistan Sarcocystis sp. and the nematode Calodium hepaticum). A European hedgehog (Erinaceus europaeus) sequence substituted the non-existent SSU rDNA sequences of shrews, and four sequences (Archaster typicus, Dinotoperla sp., Aplysia sp. and Cirratulus spectabilis) were included as representatives of evolutionary most important metazoan lineages. The PCR amplifications were performed in a total volume of $25 \mu \mathrm{l}$ using $1 \mu \mathrm{l}$ of template DNA $(\sim 200 \mathrm{ng})$ and $10 \mathrm{pmol}$ of each primer, $250 \mu \mathrm{M}$ of each DNTP, $2.5 \mu \mathrm{l} 10 \times$ PCR Buffer (Top-Bio, Czech Republic) and 1 Unit of TaqDNA (Top-Bio, Czech Republic). The PCR conditions consisted of initial denaturation at $95^{\circ} \mathrm{C}$ for $3 \mathrm{~min}, 35$ cycles of denaturation at $94^{\circ} \mathrm{C}$ for $1 \mathrm{~min}$, annealing at $56^{\circ} \mathrm{C}$ for $15 \mathrm{sec}$ and extension at $72^{\circ} \mathrm{C}$ for $20 \mathrm{sec}$ followed by terminal extension at $72^{\circ} \mathrm{C}$ for $5 \mathrm{~min}$. Amplified fragments were observed and documented on a $2 \%$ agarose gel containing $100 \mathrm{ng} / \mathrm{ml}$ ethidium bromide, excised, and purified using High Pure PCR Purification Kit (Roche). The PCR products were subsequently cloned into $\mathrm{pCR}^{\circledR} 2.1$ vector using TOPO TA Cloning ${ }^{\circledR}$ Kit (Invitrogen). M13R primer was used to sequence the cloned product on an automatic sequencer ABI PRISM 3130xl (Applied Biosystems) with BigDye ${ }^{\circledR}$ Terminator v3.1 Cycle Sequencing Kit (Applied Biosystems, Foster City, CA). SSU rDNA sequences of the XLFs and $S$. fegati (EU232760) were aligned and compared using the BioEdit sequence alignment editor (Hall 1999). The positive controls in the PCR runs were a sample of $S$. fegati DNA from a previous study (Dyková et al. 2007) and DNA of $S$. fegati extracted from Histoplast-embedded liver tissue of Soricimyxum-positive Sorex minutus. The negative controls were DNA extracted from Histoplast-embedded liver of Soricimyxum-negative Sorex minutus. Absence of $S$. fegati infection in the latter shrew was verified by both histology and PCR as in previous study (Dyková et al. 2007).

\section{RESULTS}

Sixty-six of 178 shrews examined histologically were found to be infected with Soricimyxum fegati. Of the positive specimens, 51 were Sorex araneus, 14 S. minutus and 1 Crocidura suaveolens, representing a prevalence of $52 \%, 20 \%$ and $10 \%$, respectively. Spores found in the three different host species did not differ morphologically. PCR amplification of $S$. fegati DNA extracted from liver tissue confirmed all positive diagnoses made by light microscopy and revealed the $S$. fegati infection in two dubious cases of early infection with plasmodium-like myxosporean stages in the liver parenchyma and bile ducts.

\section{Hepatic lesions}

As in the previous study (Dyková et al. 2007) that was based on examination of 54 shrews collected in August and September 2007, in tissues examined from each of the three hosts, the lesions associated with $S$. fegati infection were primarily found in the liver. In some shrews, Sarcocystis sp. infection was simultaneously present in muscles and Calodium hepaticum (Bancroft, 1893) in the liver and spleen. The extent of hepatic lesions caused by $S$. fegati varied considerably in individual specimens of a same host species. The lesions were most frequently manifested as dilatation of intrahepatic biliary ducts filled with early or advanced plasmodial stages of S. fegati. Biliary ducts were surrounded either with morphologically intact liver tissue or by host inflammatory reaction (Figs. 1-3). Longitudinal sections through bile ducts, as well as transverse sections of a same bile duct made in distant planes of sectioning, revealed asynchronous development of plasmodia in the liver tissue. In this study, no host-species-related differences were found in the nature of lesions accompanying $S$. fegati infections. Unexpected alternating presence/absence of host reaction in the vicinity of bile ducts containing mature plasmodial stages was observed, which turned our attention to the genesis of lesions. In initial phases of infection, minute proliferative stages of $S$. fegati were scattered around biliary ducts and the walls of ducts were disrupted by penetration of the parasite into the lumina (Figs. 1, 2). Biliary ducts containing intraepithelial and early intraluminal stages were surrounded by intense host reaction. These observations suggest that the host tissue reaction is triggered by proliferative stages disseminated via blood circulation, and by the damage they cause upon penetrating the lumina of bile ducts (Figs. 1, 2). The intensity of host reaction did not correlate with the size of intraluminal plasmodia and the stage of their development (see Figs. 1, 3). No plasmodial stages were found in gall bladders, which in most shrews were empty when collected and did not contain remnants of plasmodia or mature spores.

\section{Xenoma-like formations (XLFs)}

In addition to the typical hepatic lesions mentioned above, formations that resembled xenomas known in microsporidian infections (hypertrophic host cell with parasites proliferating inside and a hypertrophic host cell nucleus) were found in 19 out of 178 shrews examined. Thirteen of the 19 xenoma-like formation-positive specimens of shrews (13 S. araneus, 5 S. minutus and 1 Crocidura suaveolens) also had $S$. fegati infection in the liver. A total of 52 XLFs were studied. They were variable in size and localisation. The individual XLFs contained the same developmental stage of the causative agent, were not stratified and had an irregular hypertrophic nucleus. Slightly different stages of development of XLFs were 


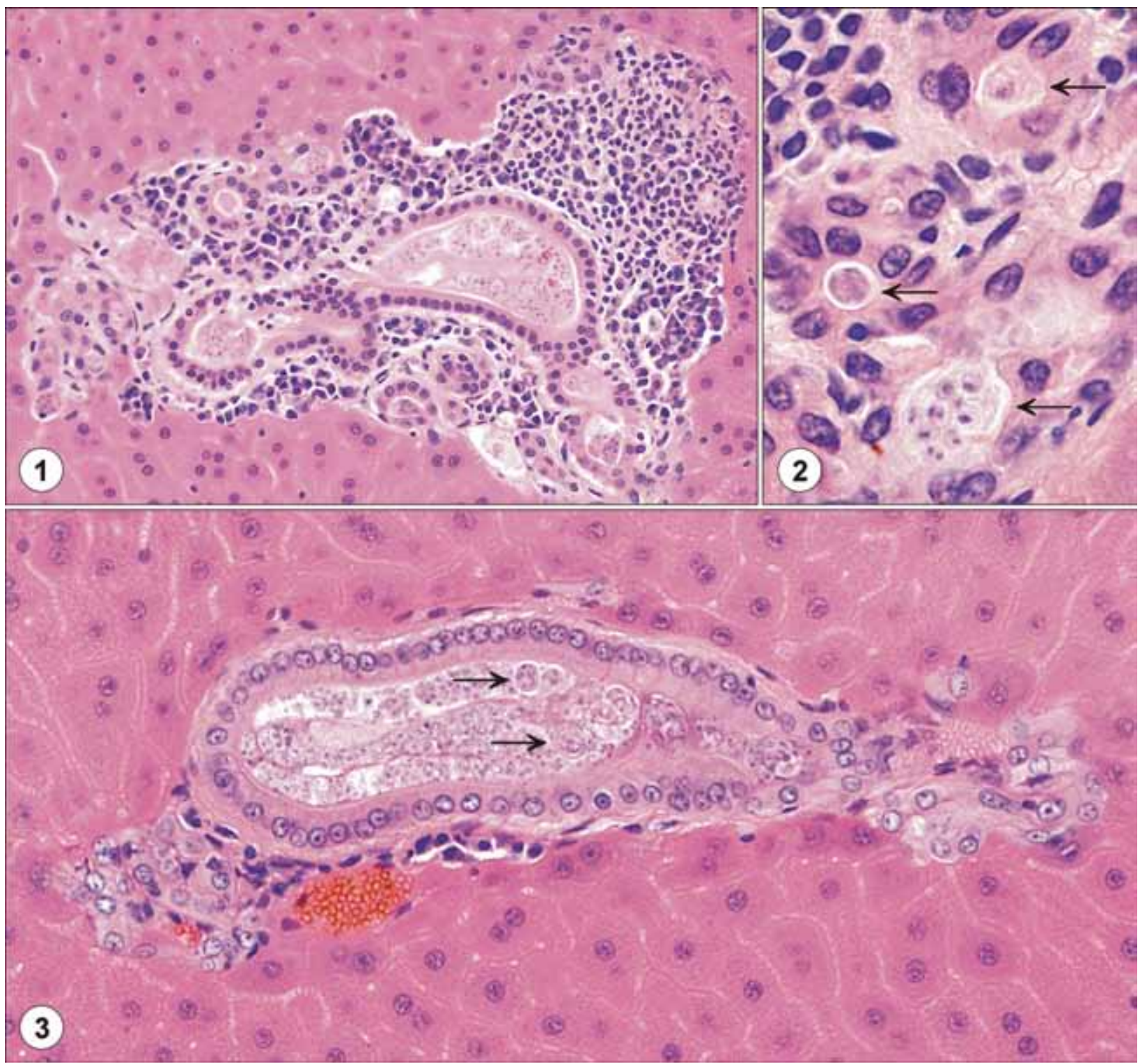

Figs. 1-3. Presence/absence of host reaction in the vicinity of biliary ducts containing plasmodial stages of Soricimyxum fegati. Fig. 1. Early infection in the liver of Sorex minutus. Plasmodia are located in the biliary ducts and proliferative stages within host inflammatory infiltrate. HE, $\times 300$. Fig. 2. Detail of proliferative stages (arrows) in the inflammatory infiltrate. HE, $\times 1050$. Fig. 3. Absence of host reaction in the liver of $S$. minutus in the vicinity of biliary ducts with advanced plasmodial stages. Note the spore formation (arrows). HE, $\times 450$.

observed in different host individuals (e.g., Figs. 5, 6); however, there was no evidence of spore maturation in any case.

Early stages of XLFs were found in the cortex of suprarenal gland of $S$. araneus between zona glomerulosa and zona fasciculata (Figs. 4, 5) and also in cardiac muscle fibres of $S$. minutus and $S$. araneus (Figs. 6-8). An elongated nucleus was observed on the periphery of a thinwalled XLF located in the suprarenal gland, and could be either fibroblast or endothelial in origin. Early XLFs in cardiac muscle fibres were enveloped by delicate fibres of endomysium discernible only by flattened nuclei of sev- eral fibroblasts. No signs of host inflammatory reaction to early XLF stages were observed in these cases (Figs. 6-8).

Most XLFs were found in the blood vessel walls, most frequently in blood vessels supplying myocardium, less frequently in those supplying liver, kidney and pancreas (Figs. 9-14). The highest number of XLFs was detected in the cardiac muscle of C. suaveolens (four XLFs in the same coronary artery, in one field of view). Tissue alterations caused by XLFs were either restricted to the tunica intima or they afflicted all component parts of vessel walls, i.e., tunica intima, t. media and t. adventitia (Figs. 9, 11-14). Thin-walled XLFs covered with endothelium 

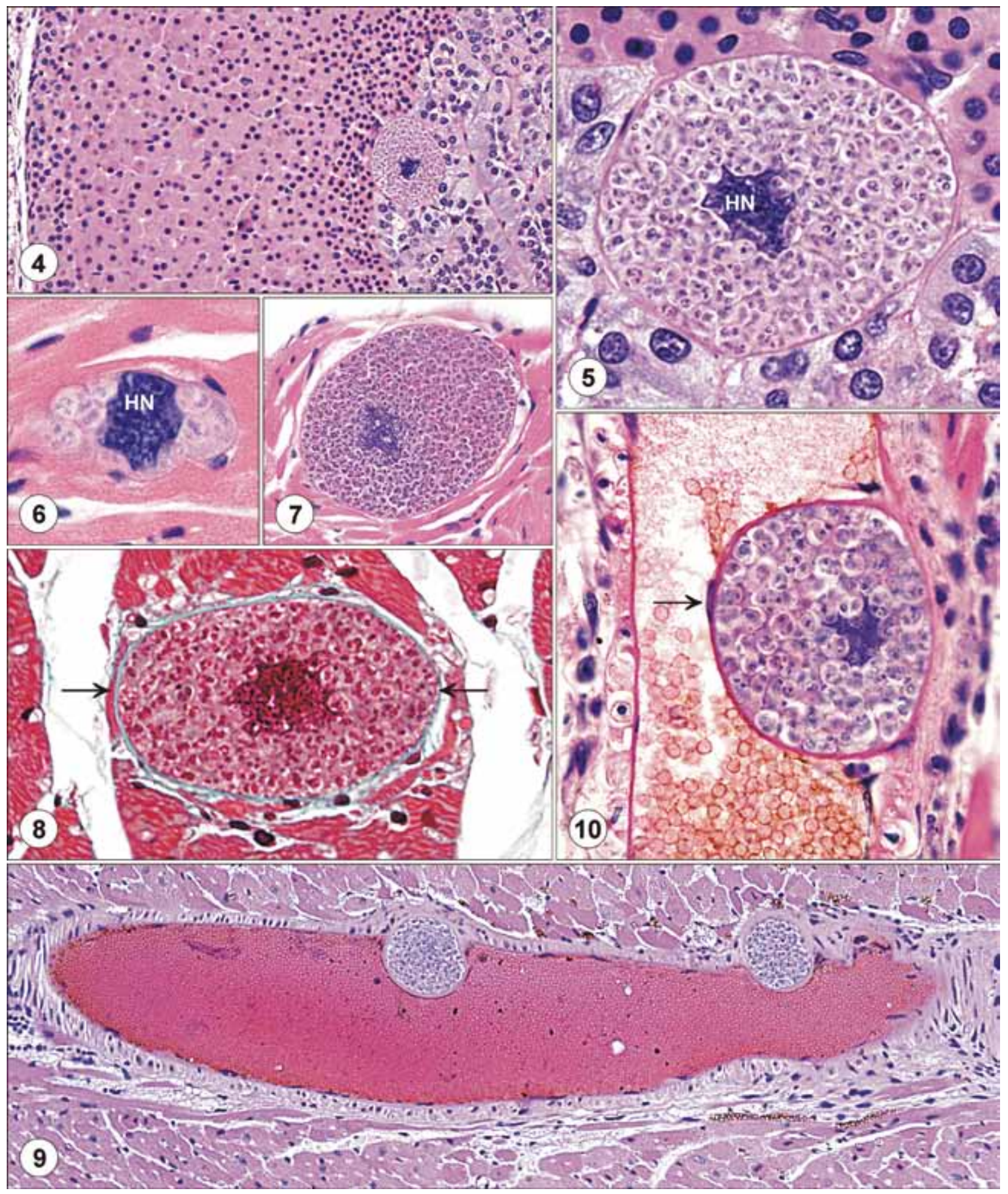

Figs. 4-10. Xenoma-like formations (XLFs) observed in various organs of shrews. Figs. 4, 5. Thin-walled XLFs localised in the suprarenal gland of Sorex araneus at an interface between zona granulosa and zona fasciculata. HE, $\times 195$ and $\times 790$, respectively. Figs. 6-8. XLFs in cardiac muscles of three specimens of Sorex minutus. The only alteration of the host tissues is due to the size of developing XLFs. Densely stained hypertrophic host cell nucleus (HN) is marked in Figs. 5 and 6. Minimal host tissue reaction (marked with arrows in Fig. 8) is seen as a thin layer of connective tissue that envelopes XLF. HE, $\times 740$ (Fig. 6), HE, $\times 300$ (Fig. 7) and Masson's trichrom, $\times 760$ (Fig. 8). Fig. 9. Coronary artery of Crocidura suaveolens with two XLFs in the vessel wall. Hypertrophic nuclei of XLFs are not seen due to the level of sectioning. HE, $\times 220$. Fig. 10. XLF protruding into the lumen of coronary artery of $C$. suaveolens, covered with endothelium (arrow marks nucleus of an endothelial cell). $\mathrm{HE}, \times 620$. 


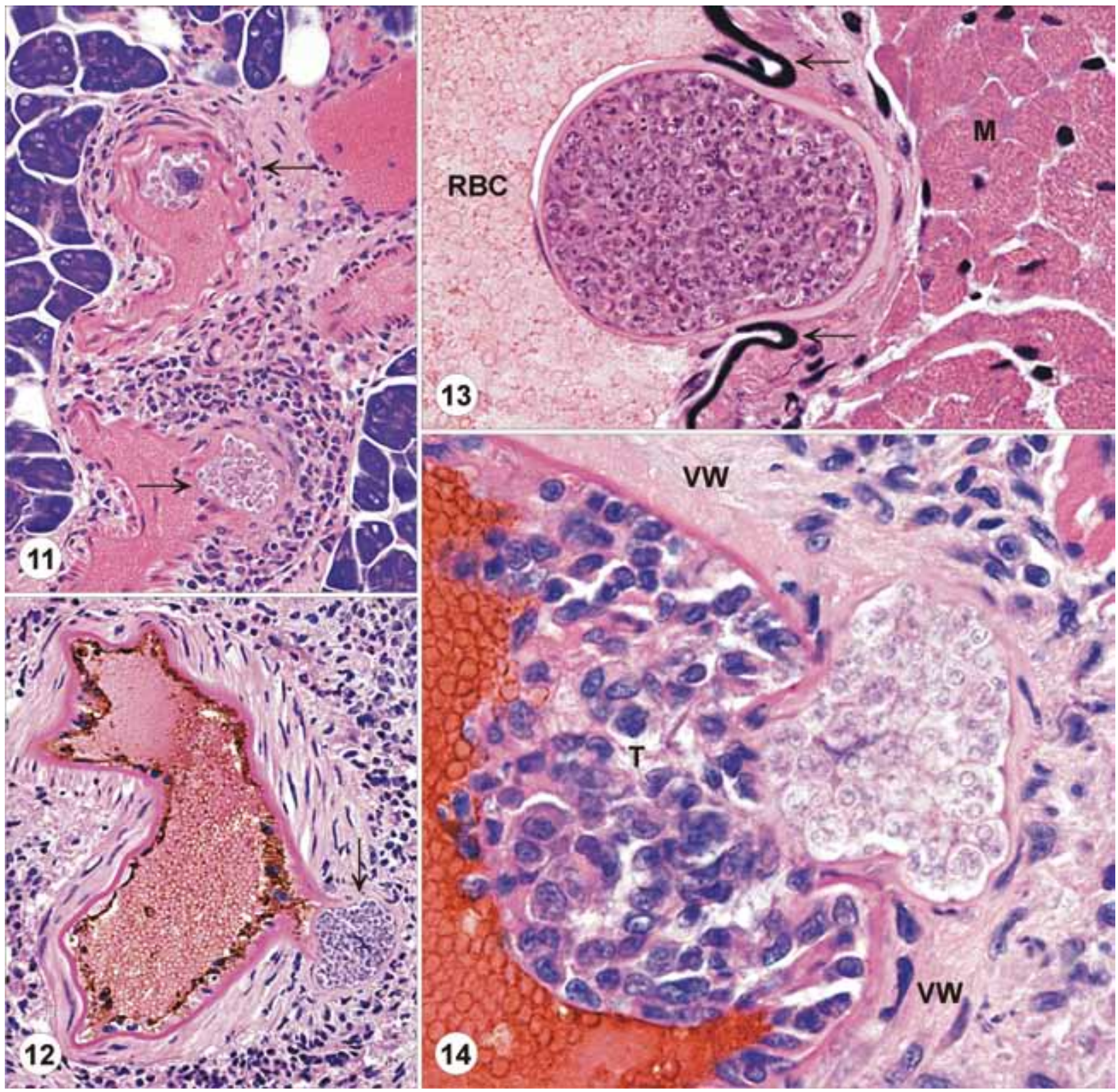

Figs. 11-14. Xenoma-like formations (XLFs) in blood vessel walls of various organs of shrews (most of XLFs are sectioned off the level of hypertrophic nucleus). Fig. 11. Two XLFs (arrows) in the walls of mesenteric blood vessels of Sorex araneus surrounded by pancreas. HE, $\times 275$. Fig. 12. Hepatic portal vein of $S$. araneus with XLF in the wall (arrow). HE, $\times 250$. Fig. 13. XLF protruding into the lumen of coronary artery of $S$. araneus. $\mathrm{M}$ - myocardium, RBC - red blood cells in the lumen of blood vessel. Development of XLF caused injury of internal elastic lamina of blood vessel (arrows) stained specifically black. Verhoeff's stain, $\times 740$. Fig. 14. Coronary artery of $S$. araneus with the most advanced vascular lesion caused by XLF. Severe injury to the vessel wall (VW) induced formation of a thrombus $(\mathrm{T})$. HE, $\times 860$.

developed in the innermost layer of blood vessels and protruded into the lumen (Fig. 10). This localisation indicates a possible fate of these thin-walled XLFs, i.e., their rupture and dissemination of developmental stages of the causative agent via blood flow. XLFs developing in deep layers of blood vessels induced lesions that took up a considerable part of the vessel wall. The blood ves- sel wall thickenings, pronounced especially in coronary arteries of the heart, were accompanied with perivascular inflammatory infiltrations (Fig. 11). The interruption of continuity of internal elastic lamina and acute thrombus formation associated with XLFs were observed in two cases (Figs. 13, 14). 


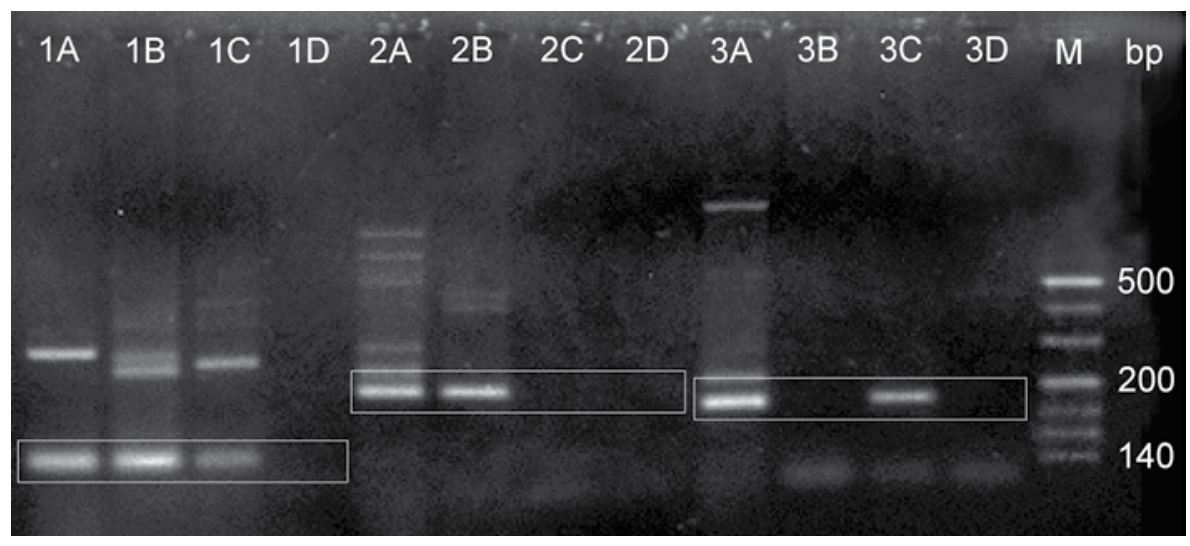

Fig. 15. PCR-based diagnostic assay. Detection of Soricimyxum fegati DNA in a sample extracted from Histoplast-embedded tissue of Sorex minutus containing xenoma-like formations (XLFs). The results of gel electrophoresis show three PCRs (lanes 1A-1D, 2A-2D, 3A-3D) conducted with three different pairs of primers. Positive controls, i.e., type DNA of $S$. fegati (Dyková et al. 2007) and DNA extracted from Histoplast-embedded liver tissue of Soricimyxum-positive Sorex minutus are marked as "A" and "B" for each reaction, respectively. "C" marks lanes with DNA extracted from XLFs in histological sections. "D" lanes show negative control with DNA extracted from Histoplast-embedded tissue of Soricimyxum-negative S. minutus. Lanes 1A-1D. Detection of $S$. fegati using Sorfeg-563F and Sorfeg-625R primers. Lanes 2A-2D. Detection of S. fegati using Sorfeg-176F and Sorfeg-377R primers. Lanes 3A-3D. Detection of S. fegati using Sorfeg-25F and Sorfeg-176R primers. Lane M. 20 bp molecular size marker.

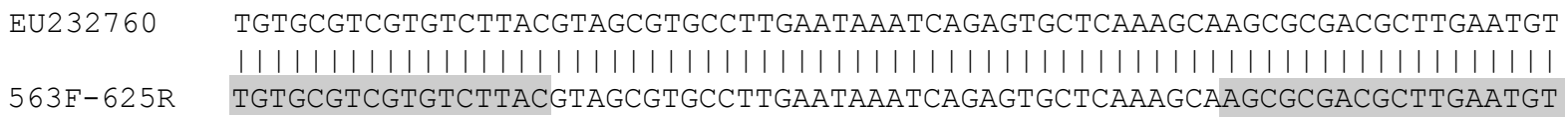

Fig. 16. Alignment resulting from BLAST search for the sequence most similar to specifically amplified DNA from xenoma-like formation in Sorex minutus. The best BLAST hit was an identical region of SSU rDNA sequence of Soricimyxum fegati (EU232760). Primer sequences used for amplification are shaded.

\section{Aetiology of xenoma-like formations}

The agent of XLFs could not be determined using light microscopy. Transmission electron microscopy of tissue samples re-embedded in Spurr resin also failed to solve the origin of XLFs (due to poor quality of fixation). The probability of hitting a well-fixed XLF in an ultrathin section was extremely low due to the small size of XLFs relative to the comparatively large size of the organs, low prevalence and time elapsed post mortem. For these reasons, our efforts to clarify the origin of XLFs relied on molecular methods.

A suitable sample of DNA was obtained from XLFs using REPLI-g ${ }^{\circledR}$ FFPE kit (QIAGEN). The other commercial kit (JETQUICK) and the procedure recommended for paraffin-embedded tissue failed in several repetitions. The PCR products obtained from XLFs' DNA were visualised together with positive controls on an agarose gel as bright bends of expected sizes (about $80 \mathrm{bp}, 220 \mathrm{bp}$ and $170 \mathrm{bp}$ for reactions with Sorfeg-563F and -625R, Sorfeg-176F and $-377 \mathrm{R}$, and Sorfeg-25F and -176R primers, respectively) (Fig. 15). Two fragments of DNA were amplified from XLF samples using the following pairs of primers: Sorfeg-563F and -625R, and Sorfeg-25F and -176R. Both amplicons were sequenced to validate their origin. Their sequences unambiguously confirmed the myxosporean origin of XLFs. The shorter sequence was completely identical with the corresponding fragment of $S$. fegati SSU rRNA gene sequence (EU232760) (see Fig.16). No other identical sequence was found by BLAST algorithm when this sequence was blasted against the GenBank collection. About 100 of the next best BLAST hits were all of myxosporean origin. The sequence of the second amplicon differed from the corresponding fragment of the type sequence of $S$. fegati (EU232760) in 7 positions. However, the particular sequence region is known to be variable both in Soricimyxum and myxosporeans in general.

\section{DISCUSSION}

Host-species specificity of Soricimyxum fegati, originally described from Sorex araneus by Prunescu et al. (2007), was suggested by some of the present authors in their previous study (Dyková et al. 2007); however, two additional host species (Sorex minutus and Crocidura suaveolens) are reported in this study. Interestingly, of these, C. suaveolens has a substantially different ecology and different nutritional requirements, its prey being almost 
exclusively arthropods (Bauerová 1988), whereas earthworms dominate in the diet of $S$. araneus and S. minutus at least for part of the year (Pernetta 1976).

This study has extended the spectrum of lesions known to be associated with Soricimyxum fegati infections. The early hepatic lesions were seen in several shrew specimens only. However, they help to understand the sequence of pathological processes and explain the alternating presence/absence of host reaction along the intrahepatic biliary ducts. The absence of host reaction in the vicinity of those parts of bile ducts that contain mature plasmodia is attributed to the fact that growing plasmodia get longer, and being flexible and most probably floating, they occupy long segments of bile ducts, including those that are far from the initial site of duct wall damage. The extremely severe lesions, described in shrews from Bialowieza Primeval Forest (Prunescu et al. 2007), which we also confirmed in the type material re-examined, were not observed in the present material from South Bohemia. The most notable findings are the xenoparasitic complexes. They have been best known in fish as a result of interaction of host cells with microsporidia (Weissenberg 1949, 1968) and have been described in series of papers summarized by Lom and Nilsen (2003). The current knowledge of xenomas induced by various protists in vertebrates other than fish, including histological and ultrastructural characters of xenoma and xenoma-like formations (XLFs), was outlined by Lom and Dyková (2005). Among non-microsporidian agents of XLFs, the latter authors mentioned two myxosporean species infecting fish: Thelohanellus pyriformis in tench (Tinca tinca) (see Dyková and Lom 1987) and Myxidium lieberkuehni in pike (Esox lucius) (see Lom et al. 1989). Unpublished data exist also on XLFs in fish infections with Ortholinea and Leptotheca species (Lom and Dyková, unpubl.). XLF is also known from the brain of the European mole (Talpa europaea) (Friedrich et al. 2000, see in Lom and Dyková 2005). It has been stressed by Lom and Dyková (2005) that, contrary to the "true" (microsporidian) xenomas, XLFs harbour cells of just one part of the parasite's life cycle. This was also the case of XLFs found in shrews.

The occurrence of XLFs was reported neither in the original description of S. fegati (see Prunescu et al. 2007) nor in the following study by Dyková et al. (2007), even though the latter authors did note XLFs in their material as well as in re-examined Prunescu et al.'s material. The publication of these observations has been postponed until the aetiology of these lesions could be cleared in this study.

Before the final conclusion about aetiology of XLFs could be made, numerous attempts were made in order to prepare and amplify corresponding samples of DNA from paraffin-embedded material. Our results confirm the negative influence of fixative such as formalin, ethanol and acetic acid (FAA) mentioned by Greer et al. (1994). Davidson's fixative used for histology of target lesions in our study is similar to FAA. In addition to FAA, it contains glycerol. It is evident that, similar as FAA, Davidson's fixative reduced the amplifiable size of DNA fragments. The minimum amount of source material obtained from minute pieces of infected tissue undoubtedly contributed to the low concentration of DNA. The suboptimal conditions for DNA stability in the fixed material led to difficulties in isolating DNA by Tissue DNA Spin Kit (JETQUICK). Although the primers used in PCR were designed to amplify relatively short fragments (up to ca $220 \mathrm{bp}$ ) as we supposed a high level of DNA fragmentation in the fixatives used, no PCR products were obtained from classically isolated DNA. The results improved when REPLI-g ${ }^{\circledR}$ FFPE kit was used, which employs random ligation reaction and nonspecific amplification of the reassembled DNA. We succeeded in amplification of XLF DNA degraded by histological procedure but the results of the PCR differed unexpectedly between the XLF samples and one of the positive controls (see Fig. 15, lanes 2B vs. $2 \mathrm{C}$ and $3 \mathrm{~B}$ vs. $3 \mathrm{C}$ ). This could be explained by different DNA templates resulting from the random ligation in the course of DNA reassemblages by REPLI- ${ }^{\circledR}$ FFPE kit.

The fact that the $132 \mathrm{bp}$ long stretch of XLF DNA that was specifically amplified by PCR differs from the corresponding region of the type SSU rDNA sequence of $S$. fegati in several positions might be explained by an intragenomic variation of this region, as suggested by our preliminary, unpublished data (20 sequences compared to date).

The role of XLFs in the myxosporean phase of S. fegati life cycle remains unclear. The crucial question whether or not the complete sporogenesis takes place in XLFs could not be answered from material currently available. This is why XLFs can either be seen as comparable with Thelohanellus pyriformis XLFs or seen as an aberrant, extrasporogonic part of the life cycle of S. fegati. The potential existence of an aberrant pathway of the life cycle of $S$. fegati, as well as the fate of XLFs, remains open to speculations. The location of XLFs in blood vessel walls associates them with blood proliferative stages, the wellknown phase in myxosporean life cycles. Physiology of shrews and possible age- or season-related changes in blood circulation, might offer a later explanation.

Acknowledgements. We thank the Department for Animal Protection, Ministry of Education, Youth and Sports of the Czech Republic for permission (Ref. No. 9690/2006-30/300) to collect shrews. Financial support was provided by the Ministry of Education, Youth and Sports of the Czech Republic (MSM 6007665801) and research projects of the Institute of Parasitology, Biology Centre of the Academy of Sciences of the Czech Republic (Z60220518 and LC522). 
Aulagnier S., Haffner P., Mitchell-Jones A.J., Moutou F., Zima J. 2009: Mammals of Europe, North Africa and the Middle East. A\&C Black Publishers Ltd., London, 272 pp.

BAuerová Z. 1988: The food of Crocidura suaveolens. Folia Zool. 37: 301-308.

DyкоVÁ I., Lом J. 1987: Host cell hypertrophy induced by contact with trophozoites of Thelohanellus pyriformis (Myxozoa: Myxosporea). Arch. Protistenkd. 133: 285-293.

Dyková I., Tyml T., Fiala I., Lom J. 2007: New data on Soricimyxum fegati (Myxozoa) including analysis of its phylogenetic position inferred from the SSU rRNA gene sequence. Folia Parasitol. 54: 272-276.

Friedrich C., Ingolic E., Freitag B., Kastberger G., Hohnmann V., Skofitsch G., Neumaister U., Kepka O. 2000: A myxozoan-like parasite causing xenomas in the brain of the mole Talpa europaea L., 1758. Parasitology 121: 438-492.

Greer C.E., Wheeler C.M., Manos M.M. 1994: Sample preparation and PCR amplification from paraffin-embedded tissues. Genome Res. 3: 113-122.

Hall T.A. 1999: BioEdit: a user-friendly biological sequence alignment editor and analysis program for Windows 95/98/NT. Nucl. Acids Symp. Ser. 41: 95-98.
Lом J., Dyкоvé I. 2005: Microsporidian xenomas in fish seen in wider perspective. Folia Parasitol. 52: 69-81.

Lom J., Dyкové I., Feist S. 1989: Myxosporea-induced xenoma formation in pike (Esox lucius L.) renal corpuscles associated with Myxidium lieberkuehni infection. Eur. J. Protistol. 24: 271-280.

Lom J., Nilsen F. 2003: Fish microsporidia: fine structural diversity and phylogeny. Int. J. Parasitol. 33: 107-127.

Pernetta J.C. 1976: Diets of the shrews Sorex araneus L. and Sorex minutus L. in Wytham grassland. J. Anim. Ecol. 45: 899-912.

Prunescu C.-C., Prunescu P., Pucek Z., Lom J. 2007: The first finding of myxosporean development from plasmodia to spores in terrestrial mammals: Soricimyxum fegati gen. et sp. n. (Myxozoa) from Sorex araneus (Soricomorpha). Folia Parasitol. 54: 159-164.

Weissenberg R. 1949: Cell growth and cell transformation induced by intracellular parasites. Anat. Rec. 103: 517-518.

Weissenberg R. 1968: Intracellular development of the microsporidian Glugea anomala Moniez in hypertrophying migratory cells of the fish Gasterosteus aculeatus L., an example of the formation of "xenoma tumours". J. Protozool. 15: 44-57.

Accepted 10 May 2011 